\section{Representações, mitos e comportamentos do paciente submetido ao implante de marcapasso na doença de Chagas}

\author{
Representations, myths, and behaviors among \\ Chagas disease patients with pacemakers
}

\begin{abstract}
This anthropological study aimed to evaluate the incorporation of pacemakers into the lives of individuals with Chagas disease. An ethnographic methodology was used, based on an open interview focusing on the personal perceptions of 15 patients with chronic Chagas cardiopathy who had required pacemaker implants at the Federal University Hospital in Belo Horizonte, Minas Gerais State, Brazil. As part of a broader quality of life analysis, the study investigated the cultural, physical, and psychological resources used by patients to confront, explain, and accept the disease process, including mental representations on the cultural perception of the illness and definition of social relations. The study was intended to contribute to comprehensive patient care by health professionals, including psychosocial aspects. Decoded and integrated orientation in the cultural sphere assumes an important role in order to prevent disinformation from perpetuating the dissemination of popular myths as active elements in patient stigmatization.
\end{abstract}

Chagas Disease; Artificial Pacemaker; Cultural Anthropology
Claudia Magnani 1

Bruna Guimarães Oliveira 2

Eliane Dias Gontijo 3

\section{Introdução}

O conceito de qualidade de vida baseia-se nos aspectos da subjetividade humana e considera a percepção pessoal do indivíduo sobre o seu estado de saúde e sobre os aspectos físicos, psicológicos e sociais que pertencem ao seu viver.

No âmbito da saúde coletiva é crescente o interesse pela avaliação da qualidade de vida do paciente, definida pela Organização Mundial da Saúde (OMS) ${ }^{1}$ (p. 1405) como "a percepção do indivíduo sobre sua posição na vida, no contexto da cultura e dos sistemas de valores nos quais ele vive, e em relação a seus objetivos, expectativas, padrões e preocupações".

Emerge no campo da saúde a necessidade de indagar a patologia através da perspectiva subjetiva. As questões médicas precisam de acompanhamento humano para não deixar de lado os problemas sociais e psicológicos ligados às situações de doença: "para conseguir acrescentar vida aos anos e não somente anos à vida” 2 (p. 20). Dentro dessa reflexão se insere a importância da abordagem antropológica, que investiga o âmbito do homem pelas suas maneiras de pensar e de agir.

A antropologia médica 3 considera o universo humano das representações mentais e dos comportamentos físicos associados à patologia, observando as repercussões que esta provoca sobre a vida dos indivíduos. Enquanto o médico procura métodos e respostas científicas para en- 
frentar as patologias encontradas, o antropólogo quer individualizar os significados que o sujeito, por seu especifico contexto cultural, dá às suas desordens corporais. Embora partindo de pontos diferentes, a medicina e a antropologia se ocupam do mesmo campo, pois ambas atuam sobre os seres humanos, "que são tanto organismos, quanto atores sociais portadores de consciência e de pensamento" 4 (p. 11).

A doença de Chagas continua a acometer parte relevante da população da América Latina, estimando-se em 16 milhões o número de infectados, o que a torna um sério problema social e político que requer um enfrentamento integral, multiprofissional, com ações intersetoriais. Sendo, por natureza, a patologia tanto social quanto biológica, a enfermidade de Chagas afeta a população oriunda de extratos mais pobres ${ }^{5}$. Nas ultimas décadas, o êxodo rural resultou em enorme contingente de chagásicos vivendo na periferia das grandes cidades; assim a doença que era típica do campo na primeira metade do século, foi gradativamente sendo reconhecida em áreas urbanas.

Portadores da forma cardíaca da doença podem apresentar distúrbio de condução e necessidade da utilização de estimulação cardíaca permanente por meio do implante de marcapasso definitivo. Apesar da disponibilidade de uma infinidade de recursos visando a diminuir o impacto da morbidade e buscando a contínua melhoria na qualidade de vida dos pacientes, a prática clínica ainda aponta alto desconhecimento, tanto da parte dos doentes como de muitos profissionais sobre a segurança e recursos envolvidos nesta tecnologia.

A medicina deve buscar, no seu percurso, a perspectiva interpretativa da antropologia para explorar a experiência humana subjetiva da incorporação da doença. O objetivo deste trabalho foi observar como chagásicos portadores de marcapasso elaboram de forma pessoal a representação simbólica dessa interferência no próprio corpo, em relação a todas as dimensões ligadas à sua vida, e de como essa perspectiva humana constrói um universo de significados culturais que se distancia da interpretação médica.

As entrevistas foram analisadas em relação ao sistema de qualificação simbólica que constitui o terreno sócio-cultural ao qual eles pertencem. Atados por um espaço de proveniência comum - o contexto de pobreza extrema - o estudo parte da observação da biografia do paciente. "Os estudos antropológicos são extraídos das e produzidos para a interação de biografias" 4 (p. 21). As vidas das pessoas que habitam o mesmo contexto sócio-cultural podem facilmente revelar-se parecidas. Por meio da observação das histórias de vida dos pacientes entrevistados tornou-se possível traçar um perfil comum do habitar a doença do indivíduo, pois é sobre as mesmas referências culturais que este se constrói.

Constatando a função social ativa das representações culturais feitas em volta da doença de Chagas, revelou-se enfim, importante, dar uma maior atenção às repercussões que esta leva no âmbito sócio-psicológico do paciente, pois se tornam grandes limitadores da qualidade de vida 6 .

\section{Metodologia}

O estudo foi realizado a partir da pesquisa etnográfica baseada no instrumento da entrevista aberta para investigar os elementos sociais, culturais e psicológicos que constroem os significados elaborados pelos pacientes para entender o implante do marcapasso no próprio corpo. As ações e as construções mentais elaboradas pelos entrevistados oferecem uma chave de leitura para a avaliação dos efeitos psicológicos, físicos e sociais da incorporação da patologia no indivíduo. Com o objetivo de conhecer a percepção dos pacientes, a análise das entrevistas seguiu uma perspectiva interpretativa e aberta, sem pretensão sistemática.

Por tratar-se de pesquisa qualitativa e pelos critérios de análise utilizados e anteriormente descritos - a consideração de biografias pertencentes ao mesmo tecido sócio-cultural - considerou-se suficiente entrevistar 15 indivíduos com cardiopatia chagásica crônica portadores de marcapasso. As informações coletadas permitiram traçar um modo de habitar comum, enquanto revelaram uma forma de enfrentar o processo de adoecimento que utiliza recursos culturais similares. Para traçar um quadro sóciocultural mais completo a respeito da qualidade de vida dos entrevistados foram levantadas informações demográficas: sexo, idade, cor, escolaridade, naturalidade, residência, ocupação, renda familiar.

As entrevistas foram realizadas no Ambulatório de Marcapasso do Hospital das Clínicas da Universidade Federal de Minas Gerais (UFMG), em local reservado, assegurando privacidade e conforto aos participantes. O trabalho foi aprovado pelo Comitê de Ética em Pesquisa (UFMG), em 15 de junho de 2005 (processo no. Etic 095/05).

\section{Perfil dos entrevistados}

Verificou-se proporção semelhante quanto ao gênero (oito mulheres e sete homens), idade média de 58 anos, variando de 27 a 75 anos, e 
predomínio de pessoas que se consideravam de cor parda (67\%). O nível de escolaridade é baixo, em média, três anos de estudo. Todos os participantes são procedentes da zona rural de pequenos municípios do interior do Estado de Minas Gerais, onde moraram em casas de pau-a-pique e trabalharam no setor agrícola, como empregados ou para subsistência familiar.

Os pacientes, em sua maioria (80\%), residem atualmente na periferia de Belo Horizonte, para onde vieram em busca de melhores condições de vida. Em relação à ocupação, muitos dos que permaneceram na zona rural foram constrangidos a interromper o trabalho por inaptidão física. Os que residem em área urbana atuam em atividades de baixa renda, como trabalhadores do setor informal ou empregados domésticos, mas, mesmo nestes postos, relatam a ocorrência de empecilhos, representados pelos efeitos sociais dos preconceitos culturais associados à doença. A renda média é de um salário mínimo. Quarenta por cento dos pacientes foram aposentados pelo Instituto Nacional do Seguro Social (INSS) por incapacidade omnioprofissional.

\section{Simbologia da doença de Chagas: encontro de uma interpretação cultural com a interpretação cientifica}

O corpo não é somente uma entidade biológica, mas um fenômeno cultural e histórico. A experiência do viver se torna, portanto, uma interpretação ativa do ambiente externo e ao mesmo tempo de produção e expressão deste. O caminho biológico não está sendo negado, porém é considerado dentro de análise mais ampla, dedicada à dimensão histórica e cultural do fenômeno. A incorporação individual é o ponto de partida para a procura do conhecimento popular da doença e a exploração do seu universo simbólico sóciocultural. Por meio da experiência do habitar a enfermidade de Chagas, o agravo é interpretado pelo sujeito e carregado de significados novos, bem distantes das definições oferecidas pela ciência médica, pois se referem a um contexto humano baseado em outros valores. A força da representação biológica do corpo e da doença deve levar em consideração o universo das premissas culturais que a sabedoria popular oferece aos seus atores sociais, os recursos intelectuais dos pacientes.

Os indivíduos reconstroem metaforicamente a doença, relacionando-a tanto com suas experiências pessoais quanto com sua bagagem cultural, suas tradições e mitos 5 .

“Às vezes estava em pé assim e caía para trás. Essa é a doença de Chagas. Todos morreram assim de repente. Deitava pra dormir, conversar, e não levantava mais" (Entrevistado 7).

"Sempre ouvia falar: A Chagas, Chagas (...) Que eles falam que quem tem Chagas, a pessoa que é assim, cai e morre de repente! Eé horrível! É igual falar: 'Você tem câncer!' (...) Pra mim naquela época foi assim. Porque eu falei: 'Puxa, eu estou condenada, vou morrer logo" (Entrevistado 9).

"O povo fala essas coisas: Que a Chagas (...) Fulano morreu de Chagas, que caía de repente e morria. Era assim que a gente ouvia falar. Mas você sabe que até hoje de vez em quando ainda tenho isso na cabeça (...) Esse pra mim é a morte sozinha, até isso eu penso, você entende? Que eles falam que quem tem Chagas, a pessoa que tá assim, cai e morre de repente!" (Entrevistado 2).

Um povo que pertence ao mesmo tecido sócio-cultural compartilha e reconhece os acontecimentos, codificando-os através do mesmo sistema de símbolos. A doença de Chagas é, portanto, reconhecida e avaliada pelo indivíduo através de uma resposta cultural que reflete as interpretações populares, e são estas referências que assumem o papel principal na codificação do agravo 7 .

A enfermidade é assintomática em $50 \%$ dos infectados, constituindo a forma crônica indeterminada. A cardiopatia chagásica crônica 8 desenvolve-se por mecanismos ainda não bem esclarecidos em número limitado de pacientes, aproximadamente em $30 \%$ dos soropositivos, sendo a principal responsável pela elevada morbimortalidade da doença de Chagas, com grande impacto social e médico-trabalhista 9 . Dentre as características mais peculiares da cardiopatia chagásica crônica destaca-se especialmente o seu caráter fibrosante, considerado o mais expressivo dentre as miocardites, a destacada freqüência e complexidade das arritmias cardíacas e sua combinação com os distúrbios da condução do estímulo atrioventricular e intraventricular 10. Entretanto, o dano miocárdico orgânico e funcional mais grave, que, entre outros desfechos, pode levar à morte súbita, manifesta-se em cerca de apenas $10 \%$ dos portadores da forma cardíaca ${ }^{11 .}$

Apesar de a morte súbita ser considerada, no âmbito científico, um evento menos comum, quando são exploradas as respostas culturais dos indivíduos que incorporam a doença encontra-se uma percepção que se opõe a esta verdade cientifica. Esse risco assume o aspecto marcante e exclusivo da doença enquanto as outras apresentações clínicas perdem o próprio valor: a doença de Chagas é simplesmente a doença "que mata de repente". A morte súbita se torna o símbolo $\mathrm{e}$ o estigma da enfermidade, que é identificada no seu pior desfecho. 
O implante do marcapasso e o tratamento farmacológico das arritmias complexas somente tornaram-se acessíveis à população de baixa renda a partir dos anos 90. Dessa forma, não é difícil entender como as experiências radicadas na memória popular ficam ligadas ao fenômeno da morte súbita dos indivíduos afetados pela tripanossomíase que, até há pouco tempo, não tinham acesso aos procedimentos e às tecnologias utilizadas para controle das manifestações clínicas. Isso impõe sérias dificuldades na incorporação das referências médicas, pois estas últimas se situam em um contexto cultural, histórico e espacial muito distante.

A primeira abordagem do homem à doença é, portanto, direcionada pelas medidas de avaliação próprias: o medo da morte é a primeira reação. Certamente a convivência com o ambiente médico, no percurso do tratamento, interfere nas informações culturais do paciente e as influencia, podendo inclusive mudar a percepção da patologia e de suas perspectivas, sem, entretanto, anular as referências primárias.

A interpretação subjetiva do fenômeno da doença, avaliada no presente trabalho, oferece uma descrição cultural importante para a compreensão de sua percepção pelos indivíduos envolvidos diretamente ou não, assim como contribui para avaliar os seus efeitos nas relações sociais.

\section{Conceito sobre a transmissão da doença}

“Não posso entender o que é a doença de Chagas. Eles falam que é dirigida de chupão né, do barbeiro (...) E esse tinha muito onde nós morávamos (...) oh gente, quantas vezes..." (Entrevistado 3 ).

Que a picada pelo vetor é a causa principal da transmissão da doença parece ser noção conhecida pelos pacientes entrevistados através da informação dos médicos: "porque eles dizem que é assim”. Porém, essa nova verdade científica sobre a forma de transmissão não se impõe totalmente sobre a interpretação popular: "Chagas para mim é que, eu achava que veio de geração assim, de pai e mãe, mas sob o andamento dos médicos, dizem que é injetado pelo barbeiro mesmo (...) então, a gente fica aí, entre a cruz e a espada, sem saber se é pelo sangue, geração pai mãe, ou se pelo barbeiro, e a gente fica no ar assim (...) Meu pai e minha mãe tinham. Morreram os dois por problema de Chagas; os dois tinham esse problema, aí eu fico pensando que seja problema de família..." (Entrevistado 4).

O conhecimento sobre a transmissão vetorial é adquirido pela informação médica. O contexto cultural dos pacientes oferece outras referências para explicar a doença. Como mencionado acima, o entrevistado demonstra que sua experiência familiar e seus saberes o levam à reflexão sobre a transmissão que vai contra a abordagem médica. O comportamento do paciente dependerá da maneira como ele lida com as duas informações 4 .

Num ambiente carente, como o que caracteriza o interior do Estado de Minas Gerais, as pessoas não têm acesso aos conhecimentos científicos que são as referências formativas do contexto dos profissionais de saúde. A experiência humana do adoecimento vivida no ambiente rural ou em pequenas comunidades é interpretada por meio dos instrumentos intelectuais elaborados dentro daquela que Geertz chama "rede de símbolos" 12: a doença de Chagas é traduzida e incorporada por meio de significados culturais que são claros produtos do terreno social específico. Neste trabalho é avaliado o encontro dessas informações com o ambiente médico, onde se confrontam com as distantes interpretações científicas.

Se o conhecimento médico é reconhecido universalmente no mundo científico atual, não quer dizer que seja aceito pela maioria da população. Este estudo mostra como a sabedoria popular ainda influi de modo importante sobre as representações - os mitos - e as práticas - os rituais - de pessoas que partes de outros pressupostos culturais.

\section{Valores, medos e mitos sobre o marcapasso}

A indicação do implante de marcapasso assume vários valores pelos pacientes. A percepção inicial é a de ter um coração fraco a ponto de necessitar de cirurgia que tornará a vida doravante dependente do funcionamento de um aparelho até então desconhecido: o marcapasso.

“Nossa, eu gritei demais, chorei demais. Eu apavorei, eu fiquei (...) porque eu fiquei muito apavorada com esse negócio. Porque eu nunca sabia que existia essa coisa. Eu fiquei apavorada demais, menina! Nosso Deus! Já chorei demais, gritei demais (...) Eu nunca tinha visto falar em marcapasso. Nunca tinha visto falar nesse aparelho. Eu chorei demais, quando o doutor João falou comigo quando cheguei em Belo Horizonte, que eu tinha que colocar esse aparelho, eu gritava tanto. Ele teve que me dar calmante, pra me acalmar, de tanto que eu chorava" (Entrevistado 2).

A introdução do marcapasso representa uma intervenção significativa que deixa um sinal físico e psicológico marcante no indivíduo. $\mathrm{O}$ impacto da colocação do aparelho provoca uma nova percepção de si e dos outros e traz novas 
preocupações que levam o sujeito portador a reorganizar suas ações e pensamentos:

"Sabe o que eu fico pensando, que você vai achar: 'Ah mas a senhora já é velha, porque pensa uma coisa dessa!' (...) De arranjar um esposo, ter um companheiro (...) Então tem um desejo, que o meu coração indicou para mim, está entendendo? (...) Aí, depois eu penso comigo assim: 'Ah não, ninguém vai querer casar comigo não! Porque eu tenho aparelho' . Então tem isso comigo (...) Eu pensava: 'Ninguém vai querer casar comigo por causa desse aparelho, ninguém vai interessar não'!" (Entrevistado 2).

A intrusão corpórea é enfrentada pelo sujeito de forma particular, íntima. A aceitação do marcapasso leva o sujeito a lidar com complexas questões psicológicas, como foi observado com os pacientes entrevistados: "No corpo senti umas coisas de repente assim, eu senti assim: eu não sabia se eu queria receber, tomar um ar, se eu queria tomar água, se eu queria fazer xixi, me deu uma coisa esquisita (...) Ah como é que chama? Depressão! Teve uma depressão que vem me pegar, de medo do aparelho que eu pensava assim: 'Aí, eu estou deitada, eu vou morrer com esse agora!' No primeiro período, eu não tinha nada não, eu estava bem, mas o meu corpo falava que eu ia morrer!" (Entrevistado 2).

Tanto como a doença, o marcapasso é carregado de representações culturais que forjam as percepções que o indivíduo tem dele. Estas interpretações subjetivas, que atingem as referências culturais trazidas do interior rural, são claramente distantes das classificações científicas que pertencem ao mundo acadêmico.

"Eu custei a acostumar com isso. Não dormia (...). Dava nervoso (...) sabia que aquilo tava ali em mim... sabia que tava com uma coisa que não era meu... Eu tinha revolta, agora não tenho mais não, agora eu gosto (...) Agora eu nem, nem penso que tenho ele..." (Entrevistado 7).

Se no início, o implante provoca um grande medo por se tratar de procedimento no coração que vai ligar a vida do homem a um aparelho, a longo prazo, o marcapasso se torna uma ampliação natural do organismo e é reconhecido como elemento fundamental da existência de quem o porta, como algo que lhe restitui a vida no momento que a estava perdendo.

Ocorre a elaboração, feita pelos sujeitos, de uma metonímia importante: a que reveste o coração do significado de vida, e que transporta este sentido ao marcapasso, pois é ele que é percebido como o motor que substitui o músculo cardíaco. O artifício se torna instrumento precioso enquanto garante a sobrevivência biológica: dentro deste sentimento, os indivíduos elaboram estratégias e rituais de tutela que vão bem além dos cuidados recomendados pelos profissionais de saúde.

"A gente fica mais sensível, protegendo sempre o lado do aparelho né (...) Eu fico sempre protegendo, porque eu tenho medo (...) quando entro num onibus mesmo eu ponho a minha bolsa aqui assim, ó, protegendo. Evito tudo. Evito mexer pra passar roupa, mexer com eletricidade pra não tomar choque. Falar no celular eu evito muito, que eu até tenho o meu celular, mas evito de falar mesmo. A minha vida agora tá dependendo muito do (...) se eu fico mais tranqüila (...) você entendeu? Chuveiro, numa hora que eu liguei tomei choque! E senti tonteira (...) Eu acho também que foi por causa do marcapasso, sou eu que acho! Médico nenhum (...) ninguém falou nada pra mim não (...) Agora quando eu vou tomar banho é o meu menino que liga o chuveiro que eu nem quero ver (...) Eu sei que talvez nem tem nada a ver, nem procurei saber, você entendeu? Mas eu evito (...) Porque eu gosto de viver né (...) se fizer alguma coisa abusando, eu sei que vai me maltratar. Então não faço! Não que seja que algum médico me prejudique nada, é por mim mesmo! Eu tô preservando eu!" (Entrevistado 5).

O marcapasso assume uma responsabilidade importante: é ele que se encarrega do trabalho que o coração não agüenta mais fazer e, por isso, se torna a fonte de vida. As práticas relacionadas ao marcapasso, portanto, não se limitam às orientações recebidas sobre o cuidado suficiente para protegê-lo, mas entram numa dimensão bem mais ampla: a tutela da própria existência.

Ainda uma vez, os pacientes interpretam - incorporam - a orientação científica através do filtro dos próprios instrumentos intelectuais: os recursos culturais, a experiência pessoal e a própria sensibilidade. As percepções individuais se relacionam com as noções científicas e, estas, são submetidas à re-elaboração ativa dos sujeitos humanos, a partir dos próprios recursos culturais 13 .

\section{Resposta justificativa: papel da fé}

“Foi depressão (...) chorando, chorando, que eu tenho medo, tenho medo, eu... eu... eu sei que a gente não é para sempre, mas eu tenho medo de morrer! (...). E o meu coração só depende dele, né (...) do marcapasso" (Entrevistado 5).

As repercussões psicológicas devidas à convivência forçada com uma doença crônica e a necessidade da colocação de um aparelho artificial no corpo levam o paciente à procura de uma explicação da própria condição de saúde, em busca de um sentido que justifique o acontecido. É fundamental aqui o papel das crenças religiosas, que são chamadas pelo indivíduo para responder ao seu próprio destino. 
Os entrevistados demonstraram procurar a justificativa sobre a própria condição de saúde e sobre a própria qualidade de vida nos valores propostos pelas noções religiosas. As respostas que oferecem um sentido sobre a própria condição de existência são encontradas na vontade de Deus. A necessidade humana procura uma razão que explique o drama da vida, neste caso a doença, e se apela à fé e à crença numa "justiça divina” que traça o destino de todo homem. Torna-se uma necessidade formular perguntas como: “Por que aconteceu?", "por que eu?". E, onde a ciência médica não dispõe de respostas, a religião, doutrina bem mais próxima do componente espiritual da existência humana, fornece explicações eficazes.

"Porque o problema é o seguinte: que não cai uma folha de uma árvore sem permissão de Deus! Se Deus permitiu essas coisas em mim, foi por vontade Dele! Então, tudo neste mundo tem seu tempo, tem o seu tempo de morrer, o tempo de nascer, o tempo de sorrir, entende? E tem também o tempo de alegria, o tempo de plantar, o tempo de colher o que plantou (...) Então, isso, nós somos servos de Deus" (Entrevistado 2).

No confronto com os vários pacientes entrevistados se evidenciaram duas formas em que o papel da religião se estabelece: de um lado, a crença em uma justiça de Deus e na tutela garantida por Ele parece oferecer uma força incrível ao indivíduo para aceitar e enfrentar as dificuldades cotidianas e os medos ligados à doença e ao marcapasso; por outro, esta crença na responsabilidade do Divino leva à resignação do doente frente à injusta e árdua condição de vida, paralisando qualquer crítica social ou política necessária ao resgate da própria dignidade humana. É preciso considerar que as condições favoráveis para a transmissão da doença de Chagas - a imensa pobreza que nega aos indivíduos o poder de tutelar a própria saúde e de terem garantidos os direitos humanos básicos - são de ordem estritamente econômica e política. A ausência de ações de controle eficazes, durante décadas, necessárias para enfrentar esse grave problema de saúde, criou um terreno fértil para a perpetuação da doença e, por conseguinte, a manutenção da pobreza e da desigualdade social.

Não se trata, então, de criticar a instituição da Igreja ou a doutrina religiosa, o importante aqui é mostrar como esta pode ser interpretada ou reinterpretada por um determinado grupo humano, e quais podem ser as conseqüências desta influência na abordagem psicológica e social da própria vida. Uma "fé cega", não acompanhada por uma consciência social que ajude a interpretar a realidade e os processos econômicos e políticos que a determinam, fomenta uma abordagem fatalista que limita o papel do indivíduo na construção do próprio destino e na luta para o resgate social 14 .

“O médico me explicando: 'Olha, deu positivo, você tem doença de Chagas'. Eu respondi para ele: 'Eu tinha'; que não conformo que eu tenho. Eu tinha. Não conformo porque o meu Deus, o nosso criador, Ele tem um poder e tem a força que já alterou, realizou milagre na minha vida, então eu creio que ele também vai tirar, já tirou tudo isso. Que Ele é o poder. E um primo meu falou comigo agora outro dia: 'Olha, Manuel, essa doença de Chagas não tem cura, ela não tem cura!', e eu falei: 'Eu sei que o povo fala que ela não tem, mas para mim ela tem, porque Deus tem o poder de curar todos os males (...) Não tem nada impossível para Deus" (Entrevistado 9).

É sempre a partir do próprio sistema de valores que os pacientes lidam tanto com as informações médicas quanto com a palavra religiosa. O indivíduo lê a experiência do adoecimento com o dicionário do seu passado 5 . Com os instrumentos de codificação da realidade, elaborados no próprio habitat, com a própria experiência de ser-no-mundo e as interferências externas que encontra ao longo da vida, com todos estes instrumentos para a leitura do mundo o indivíduo filtra a realidade que habita, a incorpora 15 . É através desse processo cognitivo que os eventos são interpretados e tomam significados pessoais: "Minha filha, já levei dois tombos, que caí para trás, eu estava na minha casa, e estava molhado, eu pisei e escorreguei, caí de costas (...) com muita força, caí e levantei de pressa (...) eu falei: 'Nossa Deus! Agora estou morta! Agora quer ver, o sangue vai descer até a minha boca, pelo nariz e vou morrer!' Que o tombo que levei fez choradeira, minha filha, nem o meu coração não mexeu (...) Mas o tombo foi tão alto, uma dor forte que parecia de ter quebrado o pescoço, de ter quebrado a costela, de tanta dor! E o meu aparelho nem mexeu! Outra vez eu estava na casa de um rapaz, e aí que caí para trás assim ó, sozinha! Vou tomar um copo de água, que vou morrer de novo. Nem o meu coração mexeu e nem o aparelho. Aí isso é Deus que está me guardando, sabia? Porque na palavra de Deus, Nossa Senhora! Está escrito assim: que o Senhor Jesus ele manda os seus anjos, que acompanham em volta dos seus filhos que os servem, então o Senhor Jesus tem mandado os seus anjos, em volta de mim (...) pra me guardar, me livrar, certo?" (Entrevistado 2).

A religião, utilizada pelo paciente como instrumento de codificação da realidade, exprime a incapacidade do indivíduo de lidar com o mundo externo. Por meio da doença de Chagas se exercitam formas de violência no corpo do homem que o sujeito não consegue compreender, e contra as 
quais ele não pode se defender. A religião é uma via eficaz para mediar e traduzir o sofrimento induzido pelo evento da doença e pela colocação do marcapasso.

\section{Repercussões sociais da doença: estigma do chagásico}

Os sentidos sociais produzidos em torno da doença se tornam símbolos que determinam específicas dinâmicas sociais, pois é nas relações entre os indivíduos que estes se definem, se redefinem e se confirmam constantemente. Nas relações sociais esses símbolos tornam-se legítimos, agem e se manifestam. Os mitos, as crenças populares, os medos, a experiência pessoal sobre o fenômeno da doença são fatores que acionam os mecanismos humanos.

A despeito de uma solidariedade forte demonstrada pelos parentes ou pelos amigos, ou seja, pelo grupo social mais próximo, nas relações de trabalho verifica-se o fenômeno inverso do distanciamento dos doentes pelos indivíduos não-infectados.

Os vários significados culturais em torno da doença de Chagas e do marcapasso estão profundamente incorporados na sociedade brasileira. O sentido popular difundido codifica o fenômeno biológico da enfermidade como uma precisa realidade sócio-cultural, baseada em referências não-médicas. Esses mitos comportam efeitos concretos e modelam as lógicas sociais de exclusão do indivíduo portador da enfermidade. A discriminação no ambiente de trabalho constitui importante estigma impingido, especialmente, ao cardiopata chagásico.

"Aí, quando fez cinco dias que eu tava operada eu fui até o meu emprego, conversei com a minha patroa, e ela falou assim: 'Você vai voltar a trabalhar apenas se você puder' e eu falei: 'Se Deus quiser eu vou! Você ainda me quer?' e ela: 'Claro que eu te quero, eu gosto muito de você, você é a pessoa ideal para cuidar do Antônio. Eu não vou trocar você por ninguém, então quer dizer que a semana que vem você volta'. Fiquei toda feliz, que conversamos que o serviço que eu não conseguia fazer a outra empregada iria fazer. (...) Então tava tudo acertado. Aí, eu tava toda feliz, toda feliz que eu ia voltar! E quando faltavam dois dias para o meu atestado médico vencer, pra eu voltar para o emprego, o telefone toca que era a minha patroa e ela falou para mim assim: 'Sinto muito, mas não vou poder te pegar em casa de volta', e eu: 'Por quê?'. 'Porque a outra empregada aqui de casa falou que é perigoso pegar você com esse aparelho colocado que você pode morrer a qualquer momento'. Ah! Eu fiquei triste demais.
E fiquei muito tempo que chorava todos os dias" (Entrevistado 14)

"Eu lá na Bahia trabalhando com os fazendeiros. Quando eu precisei deles pra me ajudar, pra assinar a minha carteira ninguém assinou. Fazendeiro lá só quer a gente para trabalhar para eles. Adoeceu, acabou. Aí quando eu adoeci lá. Me tirou das fazendas. Aí fui viver às minhas custas, por conta própria" (Entrevistado 1).

Mesmo sendo oriundos de uma camada sócio-econômica desfavorável, a questão da perda do emprego não repercute prioritariamente na esfera econômica, pelo fato da maioria dos portadores de marcapasso ter acesso ao benefício da Previdência Social. O problema aqui é de outra natureza: atinge o papel do homem na sociedade. O estigma associado ao chagásico prejudica a sua função dentro do organismo social da comunidade, a sua inclusão ao grupo. Os preconceitos dos indivíduos não-infectados constituem uma função social ativa que tende a agir tanto excluindo os indivíduos afetados pela doença no âmbito do trabalho, como afetando outros aspectos da suas vidas: "Quando fui casar, a patroa onde trabalhava chamou meu namorado e falou que não era pra ele casar, porque eu tinha poucos anos de vida, que eu ia ter muito pouco tempo de vida, que se eu vivesse mais dois anos seria muito, porque eu tinha doença de Chagas" (Entrevistado 8).

Os mitos da doença de Chagas vão além do espaço isolado do corpo de quem porta em si a doença-a mera esfera biológica - enquanto condicionam, de forma marcante, as relações sociais entre os vários atores, afetos pela doença ou não. A reflexão sobre essa patologia não pode então ser limitada ao seu caráter de evento biológico individual, mas deve ser considerada como fenômeno social que interessa uma dimensão humana bem mais ampla, a da comunidade onde os pacientes vivem. Os símbolos radicados na sociedade agem $a$ priori no desenvolvimento da discriminação do indivíduo, pois comprometem a identidade deste. Essas idéias pré-concebidas são os símbolos culturais que condicionam a vida dos pacientes, que se vêem por estes penalizados, no próprio potencial social.

"Eles [os patrões] têm medo que a gente morra de repente, enquanto você faz comida você cair e morrer de repente (...) Eles têm medo disso..." (Entrevistado 2).

As interpretações culturais são avaliações sociais eficazes pelo fato de serem reconhecidas e compartilhadas no sentido popular. É com este valor conferido pela comunidade que os símbolos da doença de Chagas modelam as relações sociais e manipulam as identidades dos portadores. 


\section{Conclusão}

Os símbolos ligados à doença de Chagas criam repercussões de ordem social que superam as fronteiras biológicas e a torna um fenômeno de ordem sócio-cultural. Os mitos, os significados culturais, os valores negativos que definem a doença no âmbito popular acarretam conseqüências psicológicas e sociais que limitam a vida dos indivíduos portadores da enfermidade. As informações científicas pertencem ao tecido social e culturalmente distante da percepção da doença, radicada em outro sistema de símbolos, relacionado ao terreno humano do paciente. A indagação da percepção do protagonista da doença, feita neste trabalho, revelou que os mitos populares ainda se impõem contra as referências médicas, atingindo a sociedade de forma mais eficaz, no papel da percepção social da doença. A orientação médica a respeito do fenômeno da doença de Chagas apresenta-se, ainda hoje, pouco radicada no sentido comum da população, onde os preconceitos culturais se tornam modeladores das relações entre os homens e criadores de discriminações sociais.

A fé assume um papel fundamental na abordagem da doença, pois se torna instrumento justificativo da própria condição existencial e força psicológica para aceitar os próprios problemas de saúde e as dificuldades ligadas a estes.

Na orientação ao indivíduo chagásico, o profissional de saúde deve considerar cuidadosamente a força dessas referências culturais incorporadas. No vínculo com o paciente crônico, o médico deve se preocupar em garantir um acompanhamento prolongado e adequado, que levante as hipóteses relativas aos significados culturais do agravo, com o objetivo de reforçar a proposta terapêutica e melhorar a percepção do paciente sobre a própria qualidade de vida.
Enfim, o estudo propôs identificar as referências sócio-culturais do paciente em relação à doença de Chagas, os mitos compartilhados na comunidade social onde ele é inserido, e as limitações que ele mesmo se impõe como contribuição para que os profissionais de saúde atendam seus pacientes de forma integral, incluindo os aspectos psicossociais, sem negligenciar a importância da orientação decodificada e integrada no âmbito cultural. É preciso evitar que a desinformação contribua para a perpetuação e a difusão dos mitos populares que se tornam "pré-conceitos" e agentes ativos de estigma e exclusão social do indivíduo chagásico.

Quando a informação é insuficiente tenderá a preencher os vazios existentes com seus saberes prévios. Por outro lado, se a informação estiver completa, permitindo a interpretação da situação como algo distinto das experiências anteriores, o paciente conseguirá enfrentar a nova situação, avaliando-a segundo suas necessidades.

No acompanhamento ao paciente a orientação deverá necessariamente levar em consideração as referências da sabedoria popular que influenciam sua abordagem da doença, com o objetivo de integrá-las às informações médicas.

Com o conhecimento adquirido no ambiente dos serviços de saúde ao longo do tempo, o indivíduo poderá ter os instrumentos cognitivos adequados para entender a circunstância da doença de forma mais científica e abandonar os medos ligados aos mitos populares. Oferecer ao paciente uma perspectiva racional pode mudar a percepção que ele tem do próprio estado de saúde e do seu potencial social; o conhecimento é o único instrumento eficaz para combater os mitos culturais que são a fonte de estigma do indivíduo. 


\section{Resumo}

Estudo antropológico sobre o modo de incorporação e as repercussões do implante do marcapasso na vida do indivíduo portador da doença de Chagas. Foi realizada uma pesquisa etnográfica baseada no instrumento de entrevista aberta, buscando identificar a percepção do estado de saúde de um grupo de 15 pacientes portadores de cardiopatia Chagásica crônica que necessitaram de implante de marcapasso, atendidos no Ambulatório de Marcapasso do Hospital das Clínicas da Universidade Federal de Minas Gerais, em Belo Horizonte, Minas Gerais, Brasil. Utilizou-se o referencial da qualidade de vida para observar os recursos culturais, físicos e psicológicos que os pacientes utilizam para enfrentar, explicar e aceitar o processo de adoecimento, incluindo as representações mentais que constroem o sentido cultural da doença e definem as relações sociais. O estudo pretende contribuir para que os profissionais de saúde atendam seus pacientes em sua integralidade. A orientação decodificada e integrada no âmbito cultural assume um papel importante para evitar que a desinformação perpetue a difusão de mitos populares, que, por vezes, se tornam preconceitos e elementos sociais ativos de estigma do indivíduo portador de cardiopatia.

Doença de Chagas; Marcapasso Artificial; Antropologia Cultural

\section{Referências}

1. The World Health Organization Quality of Life assessment (WHOQOL): position paper from the World Health Organization. Soc Sci Med 1995; 41:1403-9.

2. Fleck MPA, Louzada S, Xavier M, Chachamovich E, Vieira G, Santos L, et al. O instrumento de avaliação de qualidade de vida abreviado da Organização Mundial da Saúde (WHO-QOL breve): aplicação da versão em português. Rev Saúde Pública 2000; 34:178-83.

3. Pizza G. Antropologia medica. Saperi, pratiche e politiche del corpo. Roma: Carocci; 2005.

4. Frankenberg R. Unidas por la diferencia, dividas por la semejanza: la alegramente dolorosa posibilidad de la colaboración entre medicina y antropología. Cuadernos de Antropología Social 2003; 17:11-28.

5. Briceño-León R. La casa enferma. Caracas: Fondo Editorial Acta Cientifica de Venezuela/Consorcio de Ediciones Capriles; 1990.

6. Rossi I. La malattia cronica come marchio del corpo. Annuario di Antropologia 2003; 3:75-91.

7. Uchôa E, Firmo JOA, Dias EC, Pereira MSN, Gontijo ED. Signos, significados e ações associados à doença de Chagas. Cad Saúde Pública 2002; 18:71-9.

\section{Colaboradores}

C. Magnani participou da coleta de dados, discussão e redação do artigo. E. D. Gontijo contribuiu no planejamento, discussão e redação do artigo. B. G. Oliveira participou da discussão do artigo.
8. Cançado JR, organizador. Doença de Chagas por um grupo de colaboradores especializados. Belo Horizonte: Imprensa Oficial do Estado de Minas Gerais; 1968.

9. Secretaria de Vigilância em Saúde, Ministério da Saúde. Consenso brasileiro em doença de Chagas. Rev Soc Bras Med Trop 2005; 38 Suppl III.

10. Porto CC, Rassi A, Faria GHDC. Aspectos sócioeconômicos e médico-trabalhistas. In: Cançado JR, Chuster M, organizadores. Cardiopatia chagásica. Belo Horizonte: Imprensa Oficial; 1985. p. 362-6.

11. Gontijo ED, Rocha MOC, Oliveira UT. Perfil clínicoepidemiológico de chagásicos atendidos em ambulatório de referência e proposição de modelo de atenção ao chagásico na perspectiva do SUS. Rev Soc Bras Med Trop 1996; 29:101-8.

12. Geertz C. A interpretação das culturas. Rio de Janeiro: Jorge Zahar Editor; 1978.

13. Good B. Narrare la malattia. Torino: Edizioni di Comunità; 1999.

14. Castro A, Farmer P. El SIDA y la violencia estructural: la culpabillización de la víctima. Cuadernos de Antropología Social 2003; 17:29-47.

15. Csordas T. Embodiment and experience. Cambridge: Cambridge University Press; 1994.

Recebido em 25/Ago/2006

Versão final reapresentada em 31/Jan/2007

Aprovado em 06/Fev/2007 